\title{
Ruth Herbert
}

\section{Implementing}

Government Strategies for
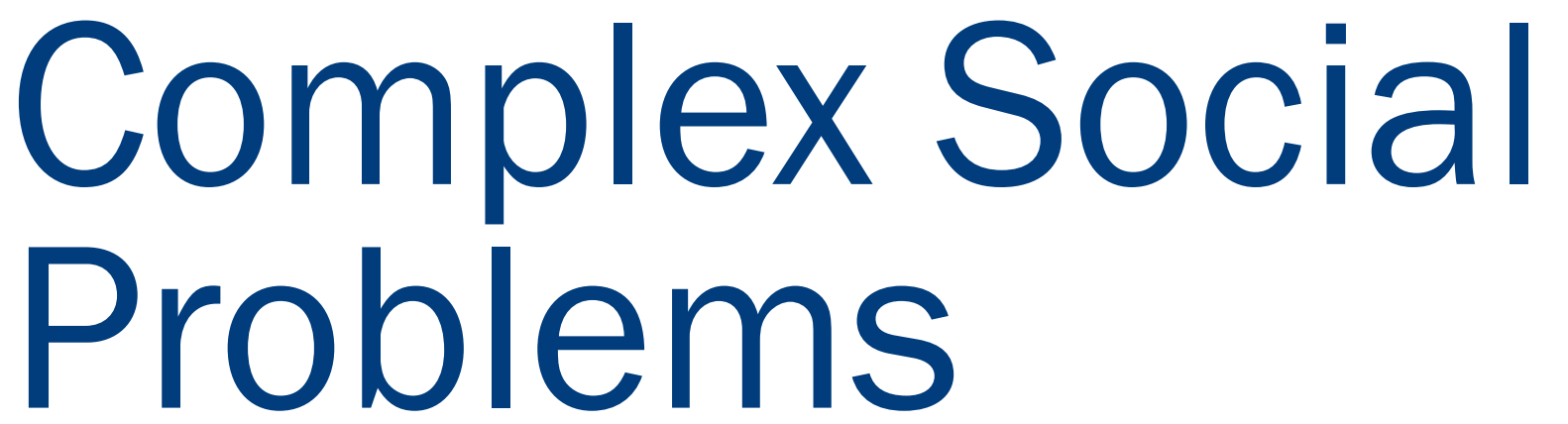

\section{Introduction}

Addressing complex social problems that are rooted in multiple causes is difficult. These issues often interact in unpredictable ways with numerous contributing factors, and they do not run along traditional departmental boundaries. For example, family violence is one of the most complex, multifaceted and poorly understood issues in Western society. Addressing family violence requires major social change in individual attitudes and relationships, cultural and religious belief systems and society's opinions, as well as comprehensive government strategies and a comprehensive range of services to support families and individuals affected by family violence. In this respect, it provided a useful case study through which to examine the implementation of complex social policy in New Zealand.

Ruth Herbert has run her own consultancy business specialising in public sector strategy, implementation and evaluation for 14 years. Her Master of Public Policy thesis won the Victoria University School of Government's 2008 Holmes Prize for 'the best research or thesis on an issue of public policy or public management of importance to New Zealand'.
Three government strategies were released between 2002 and 2006 to address the issue of family violence:

- Te Rito: New Zealand Family Violence Prevention Strategy (Te Rito), February 2002;

- The Care and Protection Blueprint (the Blueprint), February 2003; and

- The First Report (the Taskforce's First Report), July 2006.

A formative evaluation of the implementation of these three strategies (Herbert 2008) ${ }^{1}$ found that fewer than $50 \%$ of the actions - and only $42 \%$ of what I classified as the 'critical actions' in the Taskforce's First Report - had been 
fully implemented six months after the completion date stated in the strategy. Much of this situation was brought about by inadequate implementation. This article identifies the reasons for those failures. It also suggests that closer attention to the logic of Managing for Outcomes (MFO) and the availability of guidance on micro-level implementation methodology would have improved these implementation outcomes.

The research undertaken included a detailed content analysis and interpretation of published research in
Figure 1: MF0 management cycle

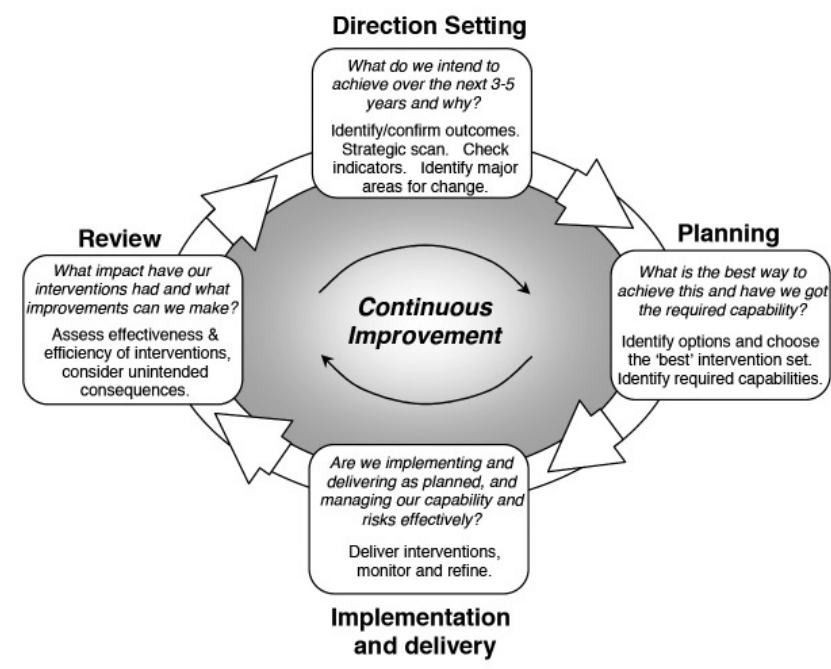

Source: State Services Commission, 2003, p.2 expectations of government departments. The guidance specific to the implementation stage was limited to a series of questions that departments were to ask themselves as they implemented new initiatives. The State Services Commission's guidance for Crown entities (State Services Commission, 2005) talks of direction setting, planning and review but is completely silent on implementation. A.L. Cook in a New Zealand Treasury working paper dealing with MFO (Cook, 2004) is also largely silent on the implementation stage of MFO. She does, however, comment (p.65):

available documentation (print and web) from government agencies. Five requests for further information under the Official Information Act 1982 were placed before the minister and Ministry of Social Development ${ }^{2}$ but four of them were refused. This meant a greater reliance than planned on confidential, semi-structured interviews with 15 government and non-government participants involved in the family violence strategies. In analysing the evidence, I drew upon my 20 years of experience in the implementation of public sector strategies and as a participant in the policy community.

\section{Managing for Outcomes - the public sector's guidance to implementers}

A key principle underpinning this research was that implementation and delivery are given a central place in the Managing for Outcomes framework (see Figure 1). In December 2001 the government introduced MFO into the New Zealand state sector, requiring central government agencies to adopt a more strategic and outcomes-focused approach to management and reporting. MFO aims to focus agency attention on outputs whilst including the intended effects, the 'outcomes', of government policy and management (see especially Baehler 2003 and Pathfinder Project, 2003a).

Ryan (2002) points out that MFO is not an add-on. It is a big and important idea that modifies many aspects of public management, but he notes that it will take some years to come to full maturity. The MFO management cycle (Figure 1) provides a useful framework for planning, implementing and evaluating major government strategies (e.g. Pathfinder Project, 2003b).

To date the MFO guidance has focused primarily on the 'direction setting' and 'planning' stages of Figure 1. In September 2003 the steering group for the MFO framework issued Managing for Outcomes: guidance for departments (State Services Commission, 2003), which outlined the if senior public servants take a lead by promoting better collaboration and coordination by designing and supporting more 'joined-up' implementation systems (where appropriate) the required cultural changes may come about in a shorter time-frame.

There appears to be very little published or unpublished literature, aside from the work of Ryan (2002), which comments specifically on the implementation phase of the MFO management cycle. ${ }^{3}$ Ryan suggests that there is still a huge amount of development work required in respect of the implementation stage and cautions (p.40):

Implementationisnot the easyphase of publicmanagement following the more difficult stage of development. The challenges are different but they need as much ongoing strategic, outcome-orientated management - maybe even more.

\section{Direction setting and planning}

As is evident in Figure 1, strategy development can be seen as the starting point of the MFO continuous improvement cycle. Moreover, the importance of the strategy being based, implicitly or explicitly, on valid theory of cause and effect is one of the key themes emerging from the literature. Ryan (2004, p.14) advises: 'Strategies are fundamentally about causality; about making intended things happen ... understanding causality is critical to being effective'. The State Services Commission's 2005 guidance to Crown entities advises that there should be a credible intervention logic or evidence as to how the objective of the policy or programme addresses the need, and defines intervention logic as the 'systematic and reasoned evidence-based description of the links between outcomes and outputs [of an intervention]'.

The causality analysis done as part of developing the strategy provides the detail of how the strategy action areas 
or new initiatives were arrived at, the assumptions behind them and in what order events need to unfold to achieve these outcomes. Like Barrett and others (e.g. Barrett, 2004), ${ }^{5}$ Ryan (2004) argues that implementation and delivery need to be carried out with knowledge of the desired policy outcomes articulated during logic modelling and expressed in policy and programme plans as immediate, intermediate and ultimate outcomes, and short-, medium- and long-term strategies.

The focus of my research was the implementation of the family violence strategies as a case study in the implementation of complex policy, and not the family violence strategy development process or the appropriateness of the strategy actions. However, I found that many of the problems experienced in the implementation phase had their roots in the strategy formation phase, and that nine of the actions had not been implemented was due to unrealistic undertakings in the strategy. Hence, examining the strategy development process became necessary to understand more about the implementation failures. intervention logic. Hence, there was no overall prioritisation of the actions, actions were assigned unrealistic completion dates, and there were no immediate or intermediate outcome targets which traditionally form the basis of the MFO model. This means there were no clear instructions to implementers about what they were expected to do, how and why the various activities should be connected, or the priority they should have accorded to the tasks. The absence of clear policy objectives left room for what Barrett (2004) calls 'differential interpretation and discretion'. This, in turn, made the task of implementation more difficult and added to the risk of implementation failure.

\section{Implementation and delivery}

Implementation is not just about achieving a series of outputs. Strategy plus activity does not automatically equate to outcome. When strategies fail to be implemented, it is easy to blame the implementers. But successful implementation is dependent upon multiple factors.

Ryan(2004)advisedthatstrategydevelopment, planning and implementation must be integrated and coordinated. The only guidance pertaining to implementation methodology provided to New Zealand government departments appears to be the following five questions included in the State Services Commission's Managing for Outcomes: guidance for departments:

Both the Blueprint and Te Rito strategy documents contained a list of goals and objectives that would equate to immediate and intermediate outcomes. In each case the goals link to the objectives, which in turn link to the action details. For example, Te Rito area of action 5 has identified links to goal 4. Objectives 4(1)(i), 4(1)(iii) and the action required are defined as: 'Develop and implement a specific plan of action for preventing violence in $\mathrm{M} \square$ ori communities, based on consultation with wh $\square$ nau, hap $\square$ and iwi' (p.26).

In contrast, the Taskforce's First Report contained a vision and a collection of seemingly unrelated new initiatives that did not necessarily link together into one overarching strategy or long-term plan. Action areas were listed as action statements with no reference to any related goals or objectives. For example:

The Ministry of Justice will:

- enhance the ability of courts to contact victims directly

- review purchasing plans for programmes

- improve processes for prosecutions for non-attendance at programmes

- establish three dedicated Family Violence Courts. (p.23)

Rather than suggesting that individual actions or initiatives were not of themselves important to bring about the change required, I observed that what was missing was the underlying causal analysis - the glue - to hold the various initiatives and action areas together. The initiatives in the Taskforce's First Report were not supported by an
- Are we implementing and delivering as planned, and managing our capability and risks effectively?

- Are roles, responsibilities and timescales for delivering interventions clear (for ourselves and any other agencies we are working with)?

- Are we monitoring our progress and risks to enable us to take corrective actions early where necessary?

- Are we keeping relevant internal and external stakeholders appropriately informed?

- Are we conducting our business in accordance with public sector ethics, values, and standards? (State Services Commission, 2003, p. 12)

My research found that of the 51 family violence actions that had not been completed or had not been progressed, in 37 of cases this was due to a breakdown in the implementation process. In order to find the factors that had contributed to the implementation failures I analysed each of the family violence actions using a composite implementation framework derived mainly from Ryan (2002) and from an implementation business model I had developed over 18 years as an implementation practitioner, based firstly on a 'planning implementation' phase, then on a 'delivering implementation' phase.

\section{Planning for implementation - the important first stage}

The extent of the planning for implementation activity is generally determined by the size and complexity of the initiative being implemented. A multifaceted nationwide programme will require more planning for implementation 
than a small trial, but some such planning will nevertheless be required. Robust planning for implementation significantly increases the probability of implementation success, and the importance of taking the time at the outset to plan for implementation cannot be overemphasised. The Cabinet Implementation Unit in the Australian Department of Prime Minister and Cabinet (PMG) stresses that 'sound implementation planning is a key element to ensuring the successful delivery of government policies' (Cabinet Implementation Unit, 2002, p.1).

My research concluded that there appeared to have been little or no planning for implementation undertaken for most of the 54 actions examined from the Taskforce's First Report. Moreover, there was little or no interconnectedness between the high-level actions articulated in the strategy development phase and the implementation planning phase.

\section{Planning in a multi-agency setting}

There are multiple government and nongovernment agencies working directly or indirectly with family violence. These agencies need to work collaboratively on multiple work streams to achieve results because no individual agency or new initiative can in itself 'prevent' family violence. If 'multi-agency' involvement is to be real and meaningful, it is important to engage these 'other agencies/people' from the outset, when planning for implementation commences, instead of bringing them in after the key decisions have been made and implementation design finalised. The first stage of planning for implementation should be to determine the most appropriate approach for each work stream ${ }^{6}$ within the strategy, together with which agencies and which areas of expertise are needed for the implementation of each initiative.

According to interviewees, there was no uniform or robust process to identify the relevant agencies to involve in the implementation of each Taskforce action. Most of the family violence initiatives were implemented by a single agency, even though multi-agency implementation would have been more appropriate for at least $75 \%$ of the actions in the Taskforce's First Report. In fact, $66 \%$ were being implemented by one agency working alone.

The non-governmental organisations interviewed did not feel that a true multi-agency approach had been taken with the implementation of the family violence strategies, and believed that this had significantly reduced the likelihood that the outcomes would be appropriate for the target community. When the organisations had been involved in the planning and implementation, it had usually been too little, too late, after all the key decisions had been made:

There is talk of multi-agency, partnership, consultation, but to date these have largely just been concepts. (interview subject 9)
Working collaboratively with a number of different agencies was seen by interviewees as more difficult, more time-consuming and requiring more resources than implementing a new initiative as a single agency. Multiagency involvement cannot be real and meaningful unless all agencies are appropriately resourced to participate fully in the planning and implementation stages. The smaller government agencies, non-governmental organisations and expert advisers that should have been involved in the implementation of the family violence strategies were not adequately resourced to participate appropriately.

The Australian PMC Cabinet Implementation Unit's Guide to Preparing Implementation Plans identifies implementation governance as the most important aspect because 'unclear governance arrangements pose a major risk to every aspect of a measure's implementation' (Cabinet Implementation Unit, 2002, p.4). The next step in planning for implementation should be for the multiple agencies involved in each work stream to collectively agree on which agency will be the 'lead agency' and what the appropriate governance arrangements for that work stream will be. This may include a multi-agency steering group, an advisory group or a working group, or perhaps a combination of two or three of these groups. Each work stream within a strategy should have an identified governance structure. Different governance arrangements will be appropriate for different work streams.

I was unable to find any documentation to ascertain how decisions regarding the governance arrangements for each family violence action were made, but information gathered from interviewees from a range of the participating agencies gave some cause for concern about the processes that were used to identify lead agencies and implementation governance for the Taskforce's 2006/07 programme of action ${ }^{7}$ :

It seems as though a lot of time is spent with different agencies ducking for cover and trying to avoid getting actions allocated to them. (interview subject 11)

The process for prioritising and allocating responsibility for initiatives appears to be more 'buck passing' with many agencies trying to avoid doing things rather than jostling 
to get their initiative advanced. (interview subject 5)

The large government agencies are the only ones with resources to commit to these actions and hence they tend to retain control for the majority of the actions. (interview subject 2)

\section{Roles and responsibilities}

Once the lead-agency and governance structure is identified, the next appropriate step is to clarify and document the roles, responsibilities and reporting lines between the lead agency, the implementation personnel and the governance group $(\mathrm{s})$. This enables all parties to be clear about who is responsible for what, and how accountability will be managed between the multiple agencies. This is particularly important as it enables the lead agency to hold all parties collectively responsible for the implementation outcomes, even when they have no line management authority over the other agencies. The family violence implementation managers and individual agencies reported feeling disconnected from the Taskforce, and there was confusion over roles, responsibilities and reporting lines between the implementation workstreams and the Taskforce, with implementation managers often feeling they had multiple masters.

Expertise and experience of implementation personnel

The new public management model introduced throughout the New Zealand public sector in the 1980s created distinct separation between policy personnel (the 'thinkers') and operational or service delivery personnel (the 'doers') in many areas of the public sector. ${ }^{8}$ It appears as though the sector has a poor understanding of: whether implementation is the responsibility of policy or service delivery personnel; what capacity and competencies are required to be an implementer; and whether the 'doers' or the 'thinkers' are best suited for this work. These questions have largely gone unanswered in the MFO guidance to public sector management.

A key principle arising out of the implementation literature and from my own practical experience is that the skills and competencies required to implement complex government strategies are very different from the traditional skills and competencies of either a policy analyst 'thinker' or an operational manager or staff 'doer'. Traditionally, the public sector's experience in implementation has focused on implementing operational policies. Hence, some public sector personnel have experience in implementing these more straightforward, single-agency operational policies, but few appear to have experience in implementing complex, multi-agency strategies for social change.

Those working on the implementation of strategic policies are, in effect, in charge of a change management programme. Implementation practitioners are often required to create change with multiple 'actors' outside their line management authority. Implementers have to be natural leaders: people who can conceptualise the macrolevel strategic vision and inspire others with that vision. To do this they need to be people whom others want to believe in, want to follow and want to perform for. Implementation personnel must also be skilled networkers and require special relationship-management and communication skills. Ryan (2004) suggests that implementation scoping work needs to be done by people who are experienced in implementation activities and skilled at working with a diverse range of people, some of whom may have conflicting views, to ensure their perspectives are taken into account.

In contrast to these macro-level skills, implementation personnel also need to constantly focus on the micro-level detail, keeping an eye on what needs to happen and in what

\section{Staff assigned to manage projects often had to learn their role the hard way, with little or no training, briefings or support and with unrealistic expectations placed on them.}

order, managing issues and risks as they arise, identifying slippage and making adjustments to ensure milestones are still achieved. And implementation practitioners must be able to link the macro and micro levels together, thereby turning the strategic vision into practical reality.

There is no repetition in the life of a strategy implementer; there is often no predictability. Implementation management can be a lonely and thankless job. Implementation project managers are held accountable for delivering a set of immediate and intermediate outcomes (or results) within a specified timeframe and often with insufficient resources. They can find themselves spinning in ever-decreasing circles, working longer and longer hours, juggling more and more balls, as deadlines loom and their superiors pressure them to deliver. They are often held responsible but have no authority in their own right.

Responsibility for implementing the family violence strategies had often been assigned to personnel who, on the evidence available, were poorly equipped to do the job. They were often novice managers or policy analysts and had little or no contact with one another, leaving them frequently feeling misunderstood and with minimal peer support. Staff assigned to manage projects often had to learn their role the hard way, with little or no training, briefings or support and with unrealistic expectations placed on them. This was the most significant issue my interview subjects identified as having a negative impact on implementation outcomes. 
Comments included:

There is a skill mismatch between those assigned responsibility for managing the implementation task and the skills required to do the job. (interview subject 14)

The role and complexity and difficulty of the implementation task is often not understood by management, and staff can feel isolated, unsupported and not sufficiently remunerated for the role they are performing. (interview subject 13)

There is a lack of (and hence difficulty in recruiting) people with knowledge of the sector and relevant project management or implementation experience to manage all the implementation work. (interview subject 7) had often been imposed by external parties, not determined by any scoping process, and sometimes without discussion with the lead agency. As a result, the implementation project managers had often been left to cut their coat according to the cloth of available resources, and to do so in the specified timeframe rather than in the timeframe necessary to achieve the outcomes. It was not surprising that all but one of the 18 actions completed (but not within the specified timeframes) appeared to have been set unrealistic completion dates in the strategy documents.

\section{The implementation plan}

The output of the planning for implementation process should be an implementation plan, formally agreed between the planners (those who developed the strategy) and the implementers. This approval gives the implementation project manager authority to proceed. The Australian PMC Cabinet Implementation Unit describes an implementation plan as a 'detailed project management tool for a specific policy measure or a package of measures, designed to assist agencies to manage and monitor implementation effectively' (Cabinet Implementation Unit, 2002, p.1).

In addition to the planning activities already discussed, the implementation plan should document: the goals and objectives; the

\section{Resourcing}

Full implementation is only possible if the budget aligns with the funding requirements. Each work stream in a strategy may require an implementation budget (covering costs of the implementation process) and an ongoing operational budget for the new initiative itself. It is important that funding requirements are identified as part of the planning for the implementation phase, and that implementation does not commence until each work stream is appropriately funded.

Interview subjects reported that some of the family violence work streams were well resourced, while others were understaffed, under-scoped and did not have an adequate budget. They also reported that on occasion undertakings had been made to implement something, but later it was discovered that there was no budget available.

\section{Committing to timeframes}

Government agencies have to constantly juggle changing requirements of their ministers, and operational providers have to constantly juggle the pressures of their day-to-day service activities with their involvement in strategy and implementation work. This evaluation found that even though family violence appeared to have had a high priority in the organisations involved, sometimes the implementation work had been reprioritised in favour of more pressing issues, thus causing slippage in timeframes. A common theme reported by interviewees was that the initial dates for the Taskforce actions in particular had been unrealistic. The timeframes steps and stages and major milestones for implementation; linkages and interdependencies with other action areas; overall timeframes; immediate, intermediate and ultimate outcomes; and potential risks and issues that will have to be managed. The plan should also identify key stakeholders and consultation requirements; communication arrangements; the management process for making alterations to the scope during implementation; and the anticipated exit or completion strategy for handing over from implementation to the ongoing operational team(s). Commencing implementation without an approved plan would be like setting off into unknown country without a map - placing the implementation personnel in a vulnerable position.

There was widespread agreement among my interview subjects about the need to formally scope and document the planned implementation approach at the outset, but little or no evidence that any comprehensive scoping had been done for the family violence action areas. Most reported implementation project plan; some said formal planning for implementation was so rare that they could cite only one or two specific examples of work streams that had been formally scoped and documented.

\section{Delivering implementation}

There is no clear dividing line between planning for implementation and actually beginning the implementation activity. In a perfect and rational world, the implementation that very few family violence work streams had a formal 
plan would be a complete 'road map' of what is required, with all factors identified prior to implementation commencing. Implementation would then be a tidy linear and sequential process. However, reality rarely resembles the ideal. A more common approach, particularly when the initiative isn't fully formed prior to commencing implementation or is not supported by good evidence, is to establish an ongoing process to modify the strategy and the implementation plan as new evidence comes to hand, thus ensuring that the strategy is always appropriate and continues to reflect the overall outcome or end point.

Continuous learning, improvement cycles, feedback loops and constant reiteration between all the phases are important implementation principles, and, if undertaken appropriately, can only enhance the implementation process. Ryan (2002, p.39) comments:

As implementation proceeds, learning is recursive, objectives and strategies are adapted, and 'the plan' becomes increasingly outdated. The sensible thing would be to modify it on an ongoing basis to match the emerging realities. Unfortunately, in Westminster-derived polities, the promissory documents presented to the budget process specify the matters for which the agency will be held accountable one-year later, come hell or high water. $\mathrm{MFO}$ in the future may require more adaptable plans and parliament will need to treat them accordingly.

This requires a balancing act between formal structure and methodology on the one hand, and flexibility to move and adapt on the other. Formal systems and processes need not stifle implementation; rather, they provide the framework for maximising opportunities for fluidity while minimising risks. What is critical is that there are mechanisms to make changes as the learning occurs.

The Australian PMC Cabinet Implementation Unit advises: 'Implementation planning should be followed by strong program and project management to ensure the successful delivery of programs.'

Project management is the most widely used methodology for managing implementation. It is a systems approach to implementation that has been widely used in the private sector for many years and is now becoming more common in the public sector. Project management provides one of the best frameworks for managing the micro-level implementation activities and for ensuring these align with the more complex and indeterminant strategic level.

This research found no evidence of any formal implementation methodology, including no risk and issue management, feedback loops between implementers (agency personnel) and those responsible for the strategy (the Taskforce), nor any formal change management process. Evidence was found, however, that the scope, milestones and timeframes of many actions had been changed during implementation. There was no evidence that the Taskforce had approved these modifications or confirmed that proposed changes would not compromise the intermediate or ultimate outcomes. The modified action areas were then reported as 'on track' in the Taskforce's quarterly monitoring reports. This had the effect of making reporting redundant, as all actions were always reported as being 'on track'. ${ }^{9}$

\section{Conclusion}

When planning for the implementation of strategic policies, the devil is in the detail. Implementing strategic policies in a fragmented public sector involving multiple agencies is difficult and has required the public sector to venture into new territory. It is as though the techniques and approaches that are being used are simply not developed enough for this new territory.

MFO focuses the government sector on setting clear desired results, implementing plans based upon these results, and learning about 'what works' in the process. There was no evidence that the Taskforce's strategies and programmes of action were developed using the MFO framework, nor that the principles of $\mathrm{MFO}$ were permeating all subsequent stages of the implementation and review cycle. This finding accords with those of the Local Futures Project (2008, p.4): 'Many agencies seem to pay only lip service to the [MFO] concept, whilst professing to be working on its implementation'; and Gill (2008): 'While considerable care went into the design of $\mathrm{MFO}$, the implementation is widely regarded as a failure leading to degeneration into compliance' (p.35) and 'While there has been no official "death notice", [MFO] is widely regarded by practitioners as "missing in action" (p.34).

Each stage of the MFO management cycle (Figure 1) is dependent upon the others, and thus the whole cycle is only as strong as the weakest link. Planning for implementation was found to be the weakest link in the cycle of planning, implementing and reviewing the family violence strategies and no individual part of the cycle was found to be strong enough to compensate for failures in any other part.

The MFO management improvement cycle is a useful strategic-level framework for planning, implementing and reviewing government strategies. However, there needs to be more guidance on micro-level implementation methodology for personnel implementing government strategies for complex social problems such as family violence. Without this, New Zealand's public servants are largely flying blind when charged with implementation.

Guidance on implementation process and methodology to Australian public servants is provided by the Australian Department of the Prime Minister and Cabinet's Cabinet Implementation Unit, part of its Strategic Policy and Implementation Group. A range of implementation resources are provided by this unit, including a Guide to Preparing Implementation Plans and a Better Practice Guide on the Implementation of Programme and Policy Initiatives. These documents do not currently extend much beyond project management, which on its own may be too simple and linear for the implementation of complex policy - useful at the micro level but not so much at the strategic level.

Implementation activities in the New Zealand public sector 
could be significantly enhanced if we were to follow the lead of the Australian government in establishing a centralised unit to help agencies and implementation personnel navigate their way through the challenging waters of strategic policy implementation.

1 This research was undertaken for a Master of Public Policy dissertation at Victoria University and was awarded the Frank Holmes Prize for 2007. My thanks go to Sir Frank and Lady Holmes for their recognition of this research.

2 The minister and Ministry of Social Development had overall responsibility for all three family violence strategies.

3 This conclusion was reached after: examining recent public policy and public management literature for guidance specific to implementation methodology; reviewing documents provided by Derek Gill who is leading the 'Managing for Performance' (M4P) project (http:// ips.ac.nz/events/Ongoing_research/M4P/index.html), which is examining what explains the poor quality of performance information and the lack of any significant progress on outcomes-focused management systems in New Zealand after nearly 20 years of reforms; and reviewing documents provided by Paul Millar from the Office of the Controller and AuditorGeneral, who is doing some work in this area.

4 http://www.ssc.govt.nz/display/Glossaryltem. asp?id=126\&this_window=.

5 For a summary of implementation research see Howlett and Ramesh, 1995, chapter 8 and Parsons, 1995, pp.457-542.

6 A work stream may include several action areas or initiatives within a strategy or just one.

7 The Ministry of Social Development (MSD) had responsibility for the overall governance arrangements for the family violence strategies but the governance arrangements for individual work streams was the responsibility of the ministry assigned as 'lead agency' for each work stream.

8 Some of the large ministries, for example MSD, have both policy and service delivery Sometions, but a substantial proportion of state services are delivered via hundreds of contracted NGOs, state-owned enterprises, crown-owned or private companies, thus creating a separation between policy and service delivery functions.

9 It is understood that the Taskforce secretariat initiated a formal change management process after this research was completed.

\section{References}

Barrett, S. (2004) 'Implementation studies: time for a revival? Personal reflections on 20 years of implementation studies', Public Administration, 82 (2), pp.249-62

Baehler, K. (2003) 'Managing for Outcomes: Accountability and Trust', Australian Journal of Public Administration, 62 (4), pp.23-34

Cabinet Implementation Unit (2000) Guide to Preparing Implementation Plans, Canberra: Department of Prime Minister and Cabinet, available at http://www.pmc.gov.au/ implementation/implementation_guide.cfm

Cook, A.L. (2004) Managing for Outcomes in the New Zealand Public Management System, working paper 04/15, Wellington: New Zealand Treasury

Gill, D. (2008) 'Managing for performance in New Zealand: the search for the Holy Grail?', in Holy Grail or Achievable Quest: international perspectives on public sector management., KPMG International

Herbert, R. (2008) Learning our Way Forward: implementation of New Zealand's family violence strategies, Wellington: Victoria University

Howlett, M. and M. Ramesh (1995) Studying Public Policy: policy cycles and policy subsystems, Ontario: Oxford University Press
Local Futures Project (2008) Managing for Outcomes in Local Government, Wellington: Victoria University, available at http:// www.localfutures.ac.nz/pdf/Local\%20 Futures\%20MFO\%20LG\%20paper\%20_2_. pdf

Ministry of Social Development (2003) Care and Protection Blueprint 2003, Wellington: Ministry of Social Development, available at http://www.msd.govt.nz/publications/ care-protection-blueprint-2003/index.html

Ministry of Social Development (2005) Action on Violence within Families: building on Te Rito, workshop, 31 March, Wellington, Ministry of Social Development

Parsons, W. (1995) Public Policy: an introduction to the theory and practice of policy analysis, Aldershot: Edward Elgar

Pathfinder Project (2003a). Guidance on Outcomes Focused Management, Building Block 1: identifying outcomes, Wellington, available at http://io.ssc.govt.nz/pathfinder/ documents/pathfinder-BB3-intervention logic.pdf

Pathfinder Project (2003b) Guidance on Outcomes Focused Management, Building Block 3: intervention logic, Wellington, available at http://io.ssc.govt.nz/pathfinder/ documents/pathfinder-BB3-intervention logic.pdf
Ryan, B. (2002) 'Managing for Outcomes in the 21st century: a discussion paper', prepared as part of the IPAA Queensland research project 'Managing Means for Policy Ends: MFO in Queensland'

Ryan, B. (2004) Learning MFO: developments in managing for outcomes: a Queensland case study, research report for the Institute of Public Administration Australia, Queensland division, Queensland: IPAA

State Services Commission (1998) New Zealand's State Sector Reform: a decade of change, available at http:// www.ssc.govt.nz/display/document. asp?docid=2384\&pagetype=toc

State Services Commission (2003) Managing for Outcomes: guidance for departments, Wellington: State Services Commission

State Services Commission (2005) Planning and Managing for Results: guidance for Crown entities, available at http://www.ssc. govt.nz/display/document.asp?docid=4856 \&pageno=4\#P107_6847

State Services Commission (2006) State of the Development Goals Report, Wellington: State Services Commission

Taskforce for Action on Violence within Families (2006) The First Report, Wellington: Ministry of Social Development 